\title{
Pictures of me: user views on their representation in homelessness fundraising appeals
}

\author{
Beth Breeze* and Jon Dean \\ School of Social Policy, Sociology and Social Research, University of Kent, UK
}

- There is a long-standing ethical debate regarding the 'right' representation of recipients in charity marketing materials that are intended to accurately define and represent social problems whilst also prompting the maximum response in voluntary income. The study presented in this article makes a contribution to that debate by highlighting the views of charity beneficiaries regarding their representation in fundraising campaigns. Drawing on data from five focus groups conducted in cities across England, we explore the views of young homeless people regarding the images of homelessness that appeared in major charity campaigns aimed at raising money to fund homelessness services. Participants displayed a high level of reflexivity, demonstrating that they understood the issues involved with bomelessness and the perceptions of people like themselves that exist in the public sphere and in the consciousness of potential donors. Although the participants held the view that maximising revenues through the use of simple, eye-catching images is the prime goal of fundraising, they also expressed a desire for more nuanced campaigns that tell the dynamic stories of how people become homeless and the use of imagery that elicits empathy rather than merely arouses sympathy.

Copyright (c) 2012 John Wiley \& Sons, Ltd.

Keywords: fundraising campaigns, nonprofit marketing, homelessness, sympathy, empathy

\section{Introduction}

The portrayal of charitable beneficiaries in fundraising campaigns can affect both the sums raised and public attitudes towards the beneficiary group (Sargeant and Jay, 2004:105) and thus has both practical and ethical implications. The ethical debate has largely focused on images of suffering children in poor countries and was reignited in 2010 after the Haiti earthquake when a leading UK charity chief executive referred to

*Correspondence to: Dr Beth Breeze, Centre for Philanthropy, Humanitarianism and Social Justice, School of Social Policy, Sociology and Social Research, Cornwallis North East, University of Kent, Canterbury, Kent CT2 7NF, UK.

E-mail: b.breeze@kent.ac.uk the use of images of suffering Haitians as 'disaster pornography'. Reflecting on this concept, a news segment on one of the UK's flagship news programme was introduced with these words:

Disaster pornography. It's a powerful and disturbing phrase... to describe what so often emerges after a terrible tragedy like Haiti... the pictures of victims that show in shocking detail what's happened to them, stripped of life and often stripped of dignity. ${ }^{1}$

\footnotetext{
${ }^{1}$ This news item was broadcast on Radio 4's Today programme on 25 January 2010.
} 
Despite the contentious methods and images used to attract donors, the Disasters Emergency Committee's Haiti fundraising appeal raised over $£ 100 \mathrm{~m}$, the second highest sum in the organisation's history. ${ }^{2}$ The tension between discomfort at the use of potentially exploitative images and the goal of maximum fundraising success lies at the heart of this debate, which has thus far been the preserve of charity professionals, media commentators and moral philosophers and excluded the voice of beneficiaries. The purpose of this article is therefore twofold: to explore this issue in a domestic context and to expand the participants in the debate by inviting beneficiaries to express their opinion on the use of 'pictures of them' within fundraising materials.

\section{Images in fundraising campaigns: policy and research context}

The generation of voluntary income is clearly the driving impetus behind fundraising campaigns. In 2001, a major UK-based overseas aid charity produced a 'good news' television broadcast, highlighting their successes and asking for donations so that the charity could continue its work. The charity considered the campaign a 'failure', as it resulted in negligible new donations (Ramrayka, 2001). This outcome appeared to confirm the unfortunate idea that

[a] poor starving Black child is so central to the idiom of charity appeals that aid campaigns depart from this convention only at the risk of prejudicing their income. (Burman, 1994: 29)

Indeed, research shows that the public are more likely to respond to advertisements that demean sufferers than those in which charitable beneficiaries are shown in a more positive light, with the same rights and capabilities as everyone else (Eayrs and Ellis, 1990).

A charity's reputation is known to be an important factor in affecting the likelihood of an individual

\footnotetext{
${ }^{2}$ The Haiti appeal is second to the appeal run in late 2004/early 2005 in which the Disasters Emergency Committee raised $£ 390 \mathrm{~m}$ for those affected by the tsunami that hit many parts of Asia on Boxing Day 2004 (http://www.bbc.co.uk/news/ 10571665).
}

donating (Kelman, 1961; Bendapudi et al., 1996; Cheung and Chan, 2000; Hibbert et al., 2007), but advertisements do not have space or scope to build up a full picture of all the services provided to beneficiaries or to depict fully the situations that have prompted users to make use of those services. Therefore, the prior knowledge and attitudes held by potential donors, regarding both the 'typical' charitable beneficiary and the 'typical' charitable organisation, become an important element in the giving decision (Bendapudi et al., 1996; Hibbert et al., 2007). The constraints involved in creating simplified images and messages mean that charity marketing materials often focus on the broad outlines of an issue and its most recognisable 'face' rather than offering detailed explanation of beneficiaries' circumstances or every facet of the charities' activities (Hibbert et al., 2007). This 'face' is likely to reflect notions of 'deserving' beneficiaries (Rosenthal 2000), most notably children, whose presence provides an emotional pull in both commercial and charitable marketing (Payton, 1989; Burman, 1994; Holland, 1992:157; O'Dell, 2008). Bendapudi et al. (1996) noted that perceptions of a cause are just as important to donors as the efficacy of the charitable organisation, hence the reductive nature of much charitable advertising, where the 'short sharp shock' has a greater impact on donors than the carefully constructed message (Small and Verrochi, 2009). However, some evidence suggests this may be more relevant for new, rather than existing, donors, as response to appeals has been found to have greater salience for newly recruited supporters (Diamond and Gooding-Williams, 2002).

Most studies explore the donor-beneficiary relationship, including the impact of images in fundraising appeals, from the donors perspective ${ }^{3}$ (for example, Eayrs and Ellis, 1990; Adler et al., 1991; Miller et al., 1993; Doddington et al., 1994; Schlegelmilch et al., 1997; Barnett and Hammond, 1999; Diamond and Gooding-Williams, 2002; Hibbert et al., 2007; O'Dell, 2008; Hung and Wyer Jr., 2009; Small and Verrochi, 2009). One reason for the focus on how images impact on donors, and for

\footnotetext{
${ }^{3}$ The one exception is Miller et al. (1993) which explores group responses to charity appeals featuring children with Down's syndrome. One of the five groups researched consists of parents of children with Down's syndrome, who are asked their response to the poster, and provide insightful comment.
} 
the negligible interest on their effect on beneficiaries, is that theories of philanthropy tend to be exclusively concerned with the philanthropist, leaving the recipient 'absent' from the formulation (Ostrander, 1989: 229). Tackling the power imbalance inherent in philanthropic transactions requires greater input from recipients (Ostrander and Schervish, 1990) taking an active part in defining how they are portrayed and how their need is represented in charity appeals (Doddington et al., 1994). Yet philanthropy is understood to be a supply-driven market, in which 'success' is a result of the reactions and moral sensibilities of donors instigated by the claims and promotions of charities working for those in need (Schervish, 1992:328). If publicity is the 'lifeblood' of charities (Deacon, 1999: 51) and crucial for fundraising success, then one conclusion is that the public must be given what they want, that is, images of charitable beneficiaries that fit comfortably with widely held stereotypes about 'victims' and that prompt the largest amount of donations. Additional information that encourages potential donors to deliberate and consider more deeply the issues involved in an issue (such as the reasons that people become homeless, as opposed to the simple fact of their lacking a place to sleep) has been shown to lessen the impact and sympathy generated by appeals (Small and Verrochi, 2009: 785-6). It is therefore argued that steps need to be taken to improve the representation of disadvantaged groups, through changing cultural imagery, and that more research needs to be undertaken to explore how such representations are differentially accepted (Barnett and Hammond, 1999).

\section{The use of images in homelessness appeals}

Representations of homelessness predominantly occur through images of 'rooflessness': the archetypal image of a homeless person is that of someone alone, on the street, sleeping amongst cardboard boxes (Swain, 2011). However, the issues involved in homelessness are clearly far more wide ranging and involve a more complicated set of problems that are harder to define (Liddiard and Hutson, 1994). The term 'homeless' is used to include those people who are sleeping in temporary accommodation, those in shelters, and those sleeping on the floors of friends. But charitable advertising and the media are unlikely to represent these more nuanced and heterogeneous details (Kemp, 1997) because, as an employee of a homeless charity notes,

It's when they become roofless... that they become an image that can be understood by most people, because the image of a young person living in a squalid bedsit would be difficult to film ...but with these young people [the street bomeless], you just send the cameras down. (quoted in Liddiard and Hutson, 1994: 61)

As the 'roofless' person is the most accessible public representation of homelessness, it is not surprising that this image is frequently utilised in marketing materials produced by homeless charities, because it is most central in the minds of potential donors. To rephrase Burman: the dishevelled man in a duffel coat on the street is so central to the idiom of charity appeals, that homelessness campaigns depart from this convention only at the risk of prejudicing their income.

The research presented in this paper attempts to rise to the challenges inherent in the existing literature, by asking the service users of homelessness charities what they think of the imagery, language and presentation of beneficiaries that are used in appeals to solicit donations.

\section{Metbodology}

Five focus groups were held in homeless hostels in Sheffield, Tonbridge, Canterbury and London. ${ }^{4}$ Participants were recruited through posters displayed within the hostels and through conversations with their key workers and other hostel staff. It was emphasised at all stages that participation was entirely voluntary and that no one was compelled to either attend or participate in the discussion. Those who chose to take part were given a $£ 10$ voucher for a local shop chosen by hostel staff as a token of thanks for giving up their

\footnotetext{
${ }^{4}$ Two focus groups were held a week apart in the London hostel, because of the large number of participants willing to take part.
} 
time. A total of 38 people participated in the research, comprising an equal gender split and a bias towards younger ${ }^{5}$ residents, ${ }^{6}$ which took place between August 2010 and September 2011.

The focus groups began with the distribution of a set of images of homelessness used in fundraising campaigns run by major charities working in this field. The images were collated in late 2009/early 2010 from direct-mail leaflets, newspaper adverts, billboard posters and internet campaigns produced by most of the UK's main homelessness charities, defined as those appearing in Charities Aid Foundation's list of the largest 300 fundraising charities in their annual publication Charity Trends, ${ }^{7}$ who also indicate 'accommodation/housing' as an area of activity on the Register of Charities held by the UK Charity Commission. The bulk of the image pack was identified by this method, with some supplemental images from fundraising campaigns run by European and American homelessness charities in order to ensure breadth of style, content and context. The participants were given some time to look through the images on their own, before a group discussion was facilitated by the researchers.

Using images to prompt discussion is a method of social research that has historically been used to solicit responses from people who respond better to visual, rather than lexical, prompts (Collier, 1957). Photo elicitation-as the method is known-can stimulate focus group discussions (Pink, 2007), allow people to express feeling and emotions that words-only research cannot (Harper, 2002:23) and is particularly useful for 'exploring participants' values, beliefs, attitudes, and meanings' (Schwartz, 1998:124).

The focus groups were recorded, transcribed and analysed by the two authors to promote intercoding reliability, which was enhanced

\footnotetext{
${ }^{5}$ Although we did not ask the participants to reveal any personal details, including their age, most looked between 16 and 30 years old, and this was indeed the target age range of the charities that helped us host the focus groups.

${ }^{6}$ All the participants in Sheffield, Tonbridge and Canterbury were resident in the hostels; some participants in the London hostel made use of 'drop-in' services.

${ }^{7}$ The edition consulted was CAF (2008) Charity Trends 2008, published by Caritas Data. The following year, this report was published under the new title 'Charity Market Monitor'.
}

by the contribution of a third researcher at the analysis stage.

\section{Findings}

This section discusses three key findings that emerge from the data: beneficiaries' belief that charity advertising should prioritise maximisation of income over other considerations; their desire for dynamic representations that explain rather than simply depict homelessness; and their preference for images that elicit empathy rather than merely arouse sympathy.

\section{Finding 1. Income maximisation is the priority}

The participants clearly expressed a preference for both accurate imagery and successful fundraising but, on the whole, felt that if charities were placed in a position of choosing between these goals, then maximising donations had to be the priority. A young man summarised this realist position:

\section{Yeab, well when you're in the situation and you ain't got no money of your own, you ain't got time to be judgemental, so if the organisations haven't got their money in the first place to belp you then the whole system breaks down, really and truly. Just get the money, book or crook, y'know?}

As service users, they were aware of their weak bargaining position and did not feel they had the power or the right to demand accurate representation:

If the money's not there, if the organisation's not there to give you a hand, or give you directions or support you, then you can't afford to be moralistic.

This view was backed up by a young mother who had discovered a photo of herself and her child in a charity newsletter for which she claimed that her permission had not been sought: 
It doesn't matter to me... I think if I'm coming here and I'm using the [homelessness charity], then they do great things for me, so I don't see it as a problem.

A number of participants expressed a belief that if you are obtaining help from a charity, the level of moral outrage you can have about the issue of representation is reduced. It was this pragmatism, when asked about the balance between accuracy and effectiveness, that became the dominant theme of all our focus groups. Ideally, the participants agreed they would be morally against adverts prompting inaccurate stereotypes of homeless people, but their current situation resulted in making tough choices-prioritising the receipt of assistance above experiencing some moral discomfort, as this quote illustrates:

I think the money's the main thing, y'know what I mean, you can't have morals when you're bomeless.

The participants understood that accurate images representing the reality of being homeless and educating donors on its causes would not necessarily encourage donors to give as much as they would if they saw more powerful images that prompted what they termed 'sympathy payments'. There was a general consensus that 'tugging on the heartstrings' of potential donors was an unfortunate necessity because 'the images need to make as much money as possible'.

One participant expressed more caution concerning the problems that a strategy aimed solely at 'maximising money' could create:

I suppose if they're making the money they're making the money, y'know that's the important thing. [But] It's not actually dealing with the problem, just keeping people with their judgmental views.

The idea that the public held preconceived 'judgmental views' about homeless people was a central narrative in discussions, and there was clear frustration that charitable imagery could reinforce existing stereotypes, as discussed further later. But the participants generally agreed that raising money had to be foremost in charities' minds above ethical considerations and ultimately viewed maximising donations as the main goal of the images under discussion.

\section{Finding 2. The desire for dynamic representations: the importance of telling stories}

Despite the dominance of the pragmatic approach, the participants overwhelmingly felt that the marketing materials they were shown were too simple and utilised overly pitiful images of vulnerable homeless people, many of which looked 'fake' or 'staged'. They also felt that most images were too generic and failed to contribute any understanding to the issues surrounding homelessness to potential donors. The participants were insistent that the public need to understand that homelessness is a much more complicated and diverse problem than is suggested by the iconic image of an old bearded man sitting on cardboard, as exemplified in the main photograph in Figure 1. Although being alert to the fact that the complex story of every homeless person cannot be contained in a single image, they were keen to see more contextual and textured portrayals, so that the public could understand them and how they got into their current situation.

Telling the stories behind 'snapshots' was widely viewed as the best way to improve the representation of homelessness. This would manifest itself in images with text to explain the transition from a 'normal man on the street' to becoming homeless. It was felt that such stories provide an opportunity for the public to relate to the experience of those portrayed, as one participant summarised:

Show [donors] that one day you can be sat in some nice gaff in Kensington, all the tea in China and something can happen maybe your loved ones die and you can lose the plot and with a short space of time you can be bomeless just like anybody else. And it's right across the board no matter who you are or what you're doing anything can happen to you to change your life. [Clicks fingers]. Like that.

Dynamic storytelling techniques were valued by participants who felt the general public did not 


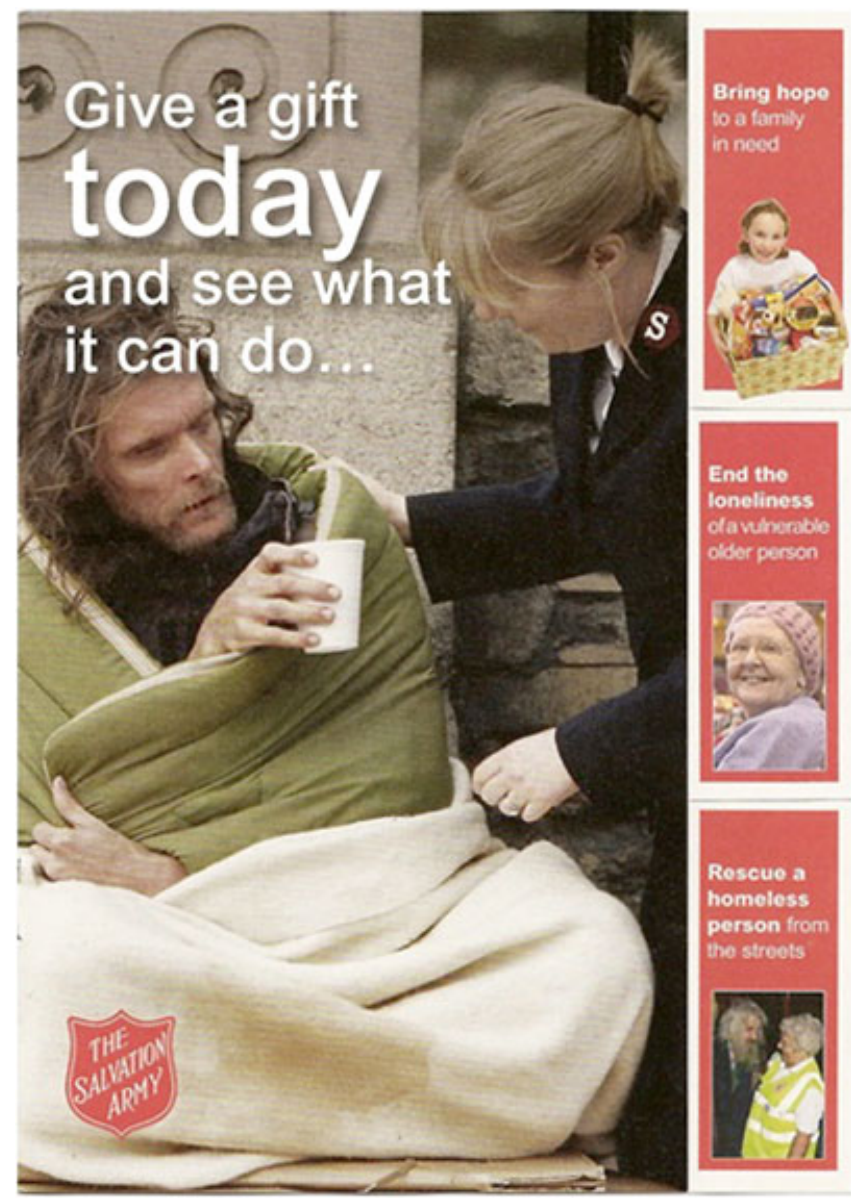

Figure 1. Image used in Salvation Army fundraising campaign. Reproduced with the kind permission of the Salvation Army

grasp that homelessness can happen to anyone and would avoid reinforcing the view of 'the homeless' as a homogenous group. A young woman spoke for many participants when she said,

Adverts are better when you see someone's story and you see where they've come from and you can relate to them with a picture.

It was clear that most of the service users did not expect to be where they were. Some were quite strident in their insistence that becoming homeless can happen quickly and without warning and felt that if a campaign that highlighted this issue could be created and continued to raise significant funds, charities would have a moral duty to follow this strategy. One young man stressed this point and noted how existing stereotypes can help people to disassociate from the issue:
I think that by focusing on how it happens will make everyone think, 'Oh god, it could happen to me', instead of 'It's alright, I haven't got a beard and I don't drink that much'.

It was also felt that telling stories could counteract the problem of simplification caused by a narrow focus in advertising and a lack of public education. This was related to a view that some images, such as stereotypes of 'roofless' people, were long past their sell-by date. Exemplifying the sophisticated analysis of many participants, one young person said,

We've seen images like that millions of times before and it desensitizes us. . Even though that's really borrible to say, it does stop affecting you.

One advert that won extensive praise included several sentences explaining why an older man 
called Steve had become homeless, as shown in Figure 2. This was popular amongst many of the participants, as 'we understand, we're learning why he's homeless'. A young woman said this style of advertising appealed to her the most:

I would definitely go for this one, because it's given a story, like I would give anyone else my story, not just a picture of me that's gross.

Other favoured adverts included those describing or portraying the positive change that interaction with the charity had brought about. Telling the happy ending' of the story was viewed as crucial, because

It gives people a more positive look towards us. Cos if I was in the street and I said 'yeah I'm bomeless, I'm in a bostel', basically people look down on me, like I'm a knobhead. . To me these faces are saying to me, she's gone through a bostel and turned herself around and now look at her, she's got a smile on her face.
Commenting on one advert that did tell the story', a young man felt it lingered too long on the depressing tale before reaching the all-important positive conclusion:

You bave to go through all that shit to get to the good bit, which is 'you've given me another chance'. That should be at the top!

\section{Finding 3. A preference for eliciting empathy rather than arousing sympathy}

The participants made many negative references to the use of imagery aimed solely at 'making me feel sorry for them', as one man said, 'most charities, they just put up the sad picture'. As the participants knew that becoming homeless could happen to anyone, because it had happened to them, they expressed a strong preference for images that elicited empathy rather than simply aroused sympathy.

\section{Everyone deserves another chance in life}

\footnotetext{
The weather was freezing when we met Steve on one of our meal runs. He was huddled on a bench wrapped in an old blanket. He gratefully took the stew and tea we served him, and started to tell us his story.

Steve once had a good career, but the pressure of work became too great, and he had a nervous breakdown. Everything unravelled from there - he lost his job and then his home.

Steve had lost so much, but he hadn't quite lost all hope. He eagerly accepted a bed for a night at one of our centres, and the offer of a bath and a clean set of clothes. It made all the difference to his morale.

At the centre, we talked to Steve about his future, and helped him to find a job and a bedsit to live in. With our help he's getting his life back together. 'You've given me another chance,' he told us, 'and this time I'm determined not to let it go.'
}

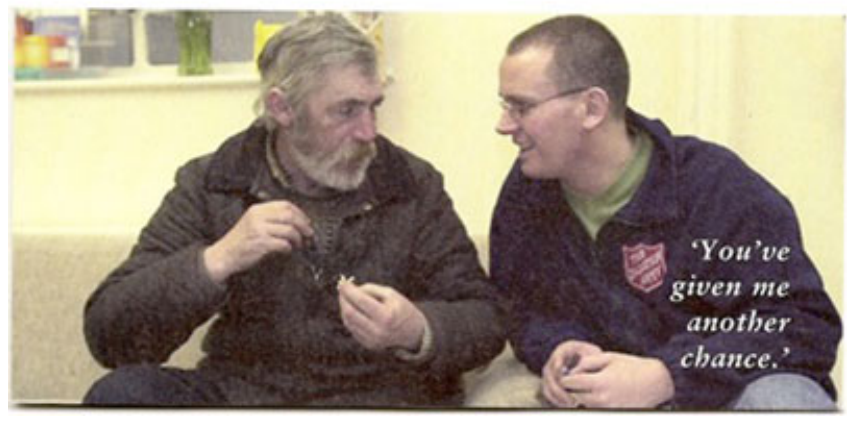

Figure 2. Image used in Salvation Army fundraising campaign. Reproduced with the kind permission of the Salvation Army 
This was partly a result of a desire for more 'truthful' images, with one young woman commenting, 'Looking at a lot of these, they look like they're actors to me, so I don't know what is real and what is not real'. The degree of pathos present in most images was a cause of irritation, and one young man stated, 'If you filmed us on the street we'd all be laughing, having a joke with each other, but we're still homeless'. It was also felt that sympathy-arousing tactics did nothing to address the underlying structural problems involved in homelessness:

For the majority of people, you show a young kid looking sad, you show an old man freezing to death, it's gonna play on people's beartstrings. . but I don't think it's gonna do anything about the issues.

It was also felt that some images intended to arouse sympathy might backfire, noting of various images of homeless men: 'He looks like a bit of a nonce' and 'he looks like a bit of a nutter, like he's there for a reason'. Where the image was especially distressing, of an older man who appeared desperate for food, one participant noted,

[That] is the image you will see every day in London, and maybe I don't want to see that. Because it evokes you to feel pity and shame, it's a bit like seeing the donkey that's beaten, and I really don't like that image. I don't want to see those photos... I want to turn away from it.

Instead of using the most pitiful image, it was strongly felt that charities should use 'proper pictures of homeless people' that show 'every kind' of person because 'there's different ways to be homeless'.

However, campaigns that sought to avoid stereotypes also came in for criticism, with participants equally unconvinced of their veracity, saying, 'They all look like they're in nice houses' and 'he looks like a doctor or something'. An image of a cheerful, wellpresented young homeless woman drew particular scorn:

You're not gonna look like that, y'know, you're not gonna have your bair all done, with big smiles on your faces. It's not going to happen.
A number of campaigns used images of children, for example, the smaller photograph at the top right of Figure 1, which led to some debate concerning the likelihood that a child would be in the care system rather than a homeless charity, yet the participants appreciated the rationale behind the picture selection. In response to the researcher asking, 'Why do you think they used this picture [of a child]?', a young woman quickly replied, 'Because she's cuter than us!'.

But generally, the participants expressed a preference for depictions of more 'normal people' that donors can empathise with. Such images were also thought to generate 'better' philanthropic motives than guilt-relieving sympathy payments and could help convince donors that their investment would one day be repaid:

People need to want to [give]. You should feel the need to want to do it to make it better, not feel guilty so you have to do it. 'I'll look like a stingy bastard so I've got to do it' - it shouldn't be like that. It's more that your money's going to belp me, so put your money in my pocket and I'll put it back as soon as I'm back on my feet.

Although the participants felt it was important that marketing materials inspired empathy, it was acknowledged that no matter which type of person was used to represent homelessness, no one face can be expected to relate to every potential donor. Using any image of a specific person was therefore viewed as a strategy that risks both misrepresenting some types of homeless people and risks alienating some portion of the donor base. This widespread view led to general acclaim for one advert that contained no people but instead featured simply a bed-length piece of cardboard lying on snowy ground with the text 'Loving the Snow? Try sleeping in it' plus the charity's website details, as shown in Figure 3. This campaign was extremely popular with the participants because they felt it honestly evoked the sensation of being homeless and cleverly illustrated the conflicting values of fun and hardship, as these two comments show:

[That advert] is exactly what homelessness is. There's no people, it's just whoever on that bit of cardboard in the snow... It is just whenever 


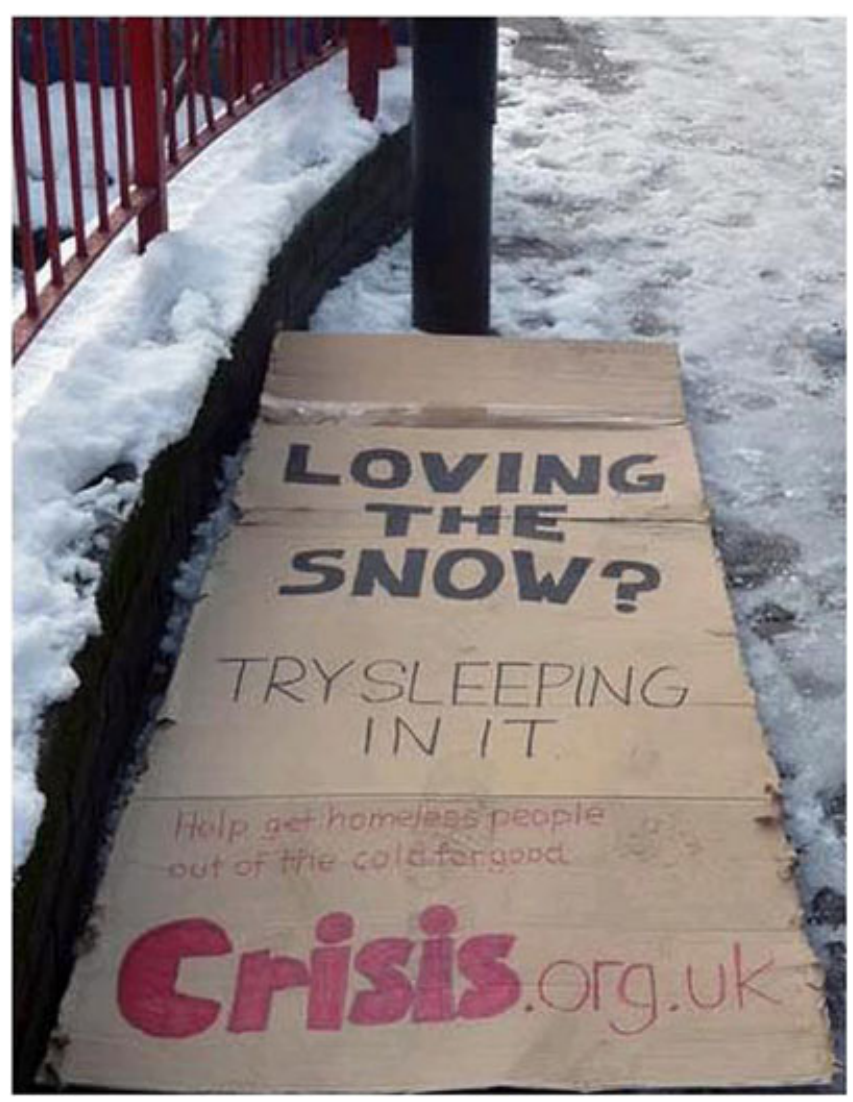

Figure 3. Image used in Crisis fundraising campaign. Reproduced with the kind permission of Crisis

you can sleep, wherever you can sleep, whoever going to sleep there.

Everyone who's been homeless has been through the same thing. I hated the snow under the bridge, know what I mean? Basically that is putting down true facts. I'm not being funny - snow is cold.

The following exchange among a group of young people discussing the 'snow advert' underlines their desire for honest imagery that elicits genuine interest and empathy:

It makes a more clearer point. Because they are not playing the guilt trip baving people looking depressed and feeling sorry for themself.

I like it because people will look at it and make a sarcastic comment but at least it proves they're fuckin' interested in us.
Whereas one of those where people look depressed, people change the channel straight over.

When I look at that one I think 'That used to be someone's bed'. They've belped that person from sleeping in the snow, and they've gone from the snow. That's how I see that picture.

It gets people thinking about it.

Many participants noted appreciatively the absence of any specific person in the 'snow image', which made it more inclusive and less likely to foment stereotypes, as these two comments show:

If it's an old person, it's 'Ob it's sad to see an old person', but this covers everyone. It could be a kid, it could be an adult, you could be black, you could be white... It covers everyone. 
If there's someone in it you could make 'em play the victim kind of card, you can make a judgement if there's someone there. If you can't relate to that person. . cos usually you just see big old men in duffel coats, I mean that's the initial thought of a bomeless person. Whereas that [indicates snow advert], anybody could be sleeping on that.

\section{Conclusion}

In all the focus group discussions, it was clear that the users of homeless charities were reflexive and cared deeply about how they were represented to the general public. However, having grown up in a postmodern consumer culture, they were highly visually literate and familiar with how marketing works and so were able to interpret the benign purpose of the portrayal of homelessness in the images under discussion. They understood why charity marketing often makes use of contrived and simplified imagery and showed appreciation of the skills of fundraisers tasked with both accurately depicting social problems and generating sufficient philanthropic sentiment towards those in need.

The finding that beneficiaries prefer dynamic storytelling techniques to 'sympathy snapshots' adds impetus to the call for a better understanding of the role of storytelling in charitable appeals (Merchant et al., 2010). Although existing research demonstrates the association between empathy and altruism in donors' charitable giving decisions (for example, as discussed in Sargeant, 1999, and in Sargeant and Woodliffe, 2007), this paper offers new insights into the beneficiary perspective on the role of these emotions in fundraising campaigns and highlights a potentially fertile overlap between the techniques preferred by beneficiaries and techniques that are known to be particularly motivating for donors. The potential of this finding to generate increased donations would be worth investigating in a split test. A further idea for future research is to explore the impact of using more empathetic images in communications (such as newsletters) aimed at retaining and educating donors who may have been recruited through more sympathy-arousing campaigns.
Recent work by Melero et al. (2011) has shown that social awareness campaigns struggle to alter public perceptions because of existing prejudices in the public's consciousness. It matters how images are mobilised in the pursuit of fundraising goals, because recipients depend upon donors both for money and for recognition of the legitimacy of their appeal and claim for support (Ostrander and Schervish, 1990:74). Yet we found the users of homelessness charities to be pragmatic about their position, which led them to accept marketing strategies that in their own terms did not achieve high moral standards. Most preferred fundraising campaigns that helped donors to understand and empathise with their situation but were willing to accept the need to use other types of images if they were proven to be the most effective at raising money.

\section{Implications for fundraisers}

Charities are the prime mobilisers of the understanding of many social issues, and fundraisers are often in the position of both defining a problem and asking people to respond to that definition. Our data illustrate the daily dilemmas experienced by those creating fundraising literature and the continuing choices that may have to be made between accuracy and effectiveness. Fundraisers can take heart that our respondents appreciate their efforts and understand the constraints within which they work. But the data also highlight the responsibility held by those putting images of charitable beneficiaries into the public realm and include suggestions as to how their representation might be improved. In particular, and insofar as it does not affect the financial bottom line, beneficiaries would prefer the use of storytelling techniques that explain how recipients come to be in a position of need and how they can turn their lives around; they prefer the use of images that elicit feelings of empathy rather that merely sympathy, and they hope for marketing that generates a generous response as a result of a recognition of common humanity rather than through emotions such as guilt or pity.

It is our hope that these findings will be helpful in reminding those crafting the portrayal of 'pictures of me' that charitable beneficiaries are not only savvy about, and grateful for, their labours but are also striving for dignity and understanding. 


\section{Acknowledgements}

This paper is an output of a project funded by the Economic Social Research Council, UK (Award number RES-593-25-0003). It is part of a wider study of 'Charity Social Redistribution' within the ESRC Centre for Charitable Giving Philanthropy. The authors are grateful for the funding, which comes from the ESRC, the Office for Civil Society, the Scottish Government and the Carnegie UK Trust. The authors are also grateful to the charities that hosted our research: the Cardinal Hume Centre in London, Porchlight in Kent, and Roundabout in Sheffield. Finally, we acknowledge the useful feedback from colleagues on an earlier version of this paper, especially Dr Claire Routley, when a draft paper was presented at the ARNOVA Toronto conference in November 2011.

\section{References}

Adler AB, Wright BA, Ulicny GR. 1991. Fundraising portrayals of people with disabilities: donations and attitudes, Rehabilitation Psychology 36(4): 231-240.

Barnett J, Hammond S. 1999. Representing disability in charity promotions. Journal of Community \& Applied Social Psychology 9: 309-314.

Bendapudi N, Singh SN, Bendapudi V. 1996. Enhancing helping behaviour: an integrative framework for promotion planning, Journal of Marketing 60(July): 33-49.

Burman E. 1994. Poor children: charity appeals and ideologies of childhood. Changes: An International Journal of Psychology and Psychotherapy 12(1): 29-36.

CAF (Charities Aid Foundation). 2008. Charity Trends 2008. Caritas Data: London.

Cheung CK, Chan CM. 2000. Social-cognitive factors of donating money to charity, with special attention to an international relief organization. Evaluation and Program Planning 23(2000): 241-253.

Collier J, Collier M. 1957. An experiment in applied anthropology. Scientific American 59: 37-49.

Deacon D. 1999. Charitable images: the construction of voluntary sector news. In Social Policy, The Media and Misrepresentation, Franklin B (ed.) Routledge: London.

Diamond WD, Gooding-Williams S. 2002. Using advertising constructs and methods to understand direct mail fundraising appeals. Nonprofit Management $\mathcal{E}$ Leadership 12(3): 225-242.
Doddington K, Jones, RSP, Miller BY. 1994. Are attitudes to people with learning disabilities negatively influenced by charity advertising? Disability \& Society 9(2): 207-222.

Eayrs CB, Ellis N. 1990. Charity advertising: for or against people with a mental handicap? The British Journal of Social Psychology 29: 349-360.

Harper D. 2002. Talking about pictures: a case for photo elicitation. Visual Studies 17(1): 13-26.

Hibbert S, Smith A, Davies A, Ireland F. 2007 Guilt appeals: persuasion knowledge and charitable giving. Psychology and Marketing 24(8): 723-742.

Holland P. 1992. What is a Child? Popular Images of Childbood. Pandora Press: London.

Hung IW, Wyer Jr RS. 2009. Differences in perspective and the influence of charity appeals: when imagining oneself as the victim is not beneficial. Journal of Marketing Research 46(June): 421-434.

Kelman HC. 1961. Processes of opinion change. Public Opinion Quarterly 25: 57-78.

Kemp P. 1997. The characteristics of single homeless people in England. In Homelessness and Social Policy, Burrows R, Pleace N, Quilgars D (eds). Routledge: London.

Liddiard S, Hutson M. 1994. Youth Homelessness: The Construction of a Social Issue Macmillan: Basingstoke.

Melero R, Montero MJ, Araque RA, Gutierrez B. 2011. Breaking down social stereotypes: the case of the Fundación Secretariado Gitano in Spain. International Journal of Nonprofit and Voluntary Sector Marketing 16: 225-236.

Merchant A, Ford JB, Sargeant A. 2010. Charitable organizations' storytelling influence on donors' emotions and intentions. Journal of Business Research 63: 754-762

Miller BY, Jones RSP, Ellis NC. 1993. Group differences in response to charity images of children with Down syndrome. Down Syndrome Research and Practice. 1(3): 118-122.

O'Dell L. 2008. Representations of the 'Damaged' Child: 'Child Saving' in a British Children's Charity ad Campaign. Children \& Society 22: 383-392.

Ostrander SA. 1989. Why philanthropy neglects poverty: some thoughts from history and theory. In The Future of the Nonprofit Sector, Hodgkinson V, Lyman R (eds). Jossey-Bass: San Francisco.

Ostrander SA, Schervish PG. 1990. Giving and getting: Philanthropy as social relation. In Critical issues in American philanthropy, Van Til J (ed.) Jossey-Bass: San Francisco. 
Payton RL. 1989. Helping the undeserved abroad: the case of famine relief. In The Future of the Nonprofit Sector, Hodgkinson V, Lyman R (eds). Jossey-Bass: San Francisco.

Pink S. 2007. Visual Interventions: Applied Visual Anthropology. Berghahn Books: New York, Oxford.

Ramrayka L. 2001. Charities struggle to find right balance with ad campaigns. The Guardian. http:// www.guardian.co.uk/society/2001/jun/15/charities. Accessed 9 November 2011.

Rosenthal R. 2000. Imaging homelessness and homeless people: visions and strategies within the movement(s). Journal of Social Distress and the Homeless 9(2): 111-126.

Sargeant A. 1999. Charitable giving: towards a model of donor behaviour. Journal of Marketing Management 15(4): 215-238.

Sargeant A, Jay E. 2004. Fundraising Management: Analysis, Planning and Practice. Routledge: London and New York.
Sargeant A, Woodliffe L. 2007. Gift giving: an interdisciplinary review, International Journal of Nonprofit and Voluntary Sector Marketing 12: 275-307.

Schervish PG. 1992. Adoption and altruism: those with whom I want to share a dream. Nonprofit and Voluntary Sector Quarterly 21(4): 327-250.

Schlegelmilch BB, Love A, Diamantopoulos A. 1997. Response to different charity appeals: the impact of donor characteristics on the amount of donations. European Journal of Marketing 31(8): 548-560.

Schwartz J, Schwartz D. 1998. Photographs within the sociological research process. In Image-based Research: $A$ Sourcebook for Qualitative Researchers, Prosser J (ed.) RoutledgeFalmer: London.

Small DA, Verrochi NM. 2009. The face of need: facial emotion expression on charity advertisements. Journal of Marketing Research 46(December): 777-787.

Swain J. 2011. Busting the myth. Inside Housing, http://www.insidehousing.co.uk/care/busting-the-myth/ 6519274.article. Accessed 5 December 2011. 